\title{
Drying Kinetics of Sliced Pineapples in a Solar Conduction Dryer
}

\author{
Luqman E. I. Daud ${ }^{1} \&$ Isaac N. Simate ${ }^{1}$ \\ ${ }^{1}$ Department of Agricultural Engineering, School of Engineering, University of Zambia, Lusaka, Zambia \\ Correspondence: Luqman E. I. Daud, Department of Agricultural Engineering, School of Engineering, \\ University of Zambia, Lusaka, Zambia. Tel: 260-973-596-108. E-mail: luqman.ebow.daud@gmail.com
}

Received: August 26, 2017 Accepted: September 7, 2017 Online Published: September 29, 2017

doi:10.5539/eer.v7n2p14 URL: https://doi.org/10.5539/eer.v7n2p14

\begin{abstract}
As a means of adding value to pineapple production and minimising post-harvest losses, sliced pineapples were dried using a Solar Conduction Dryer (SCD) and appropriate thin layer drying models to predict drying were developed whilst the performance of the SCD was also investigated. For the period of the experiment, ambient temperature and temperature in the dryer ranged from 24 to $37{ }^{\circ} \mathrm{C}$ and 25 to $46{ }^{\circ} \mathrm{C}$ respectively. The performance of the dryer was compared to open sun drying using pineapple slices of 3-5 $\mathrm{mm}$ in thickness where the slices were reduced from an average moisture content of $85.42 \%$ (w.b.) to $12.23 \%$ (w.b.) by the SCD and to $51.51 \%$ (w.b.) by the open sun drying in 8 hours effective drying time. Pineapple slices of thicknesses $3 \mathrm{~mm}, 5 \mathrm{~mm}, 7$ $\mathrm{mm}$ and $10 \mathrm{~mm}$ were simultaneously dried in the four drying chambers of the SCD and their drying curves simulated with twelve thin layer drying models. The Middilli model was found as the best fitted thin layer drying model for sliced pineapples. The optimum fraction of drying tray area that should be loaded with pineapples was also investigated by simultaneously loading $7 \mathrm{~mm}$ slices of pineapples at 50,75 , and 100 percent of drying tray area. Loading the slices at 50,75 and 100 percent of drying tray area gave overall thermal efficiencies of 23, 32 and 44 percent, respectively, hence loading pineapple slices at 100 percent drying tray area was recommended as the best.
\end{abstract}

Keywords: ambient, conduction, convection, drying curve, effective drying time, thin layer

\section{Introduction}

Pineapple is a seasonal tropical fruit rich in proteins, vitamins and minerals (Barnell, 1974; Ihekoronye \& Ngoddy, 1985), but being very perishable, pineapples require preservation in some form. According to Esper (1996), drying of agricultural products is still the most prevalent preservation practice and it is increasingly becoming an option to marketing fresh fruits since the demand for high quality dried fruits is gradually increasing all over the world. In addition to preservation, drying reduces the mass and volume of materials and enhances efficiency of storage and transportation. Drying is the evaporation of moisture from solid material upon the application of heat and is primarily driven by a number of factors such as humidity, temperature and air velocity. Several mathematical models for predicting fruit-drying behaviour have been extensively investigated in the field of processing agricultural products either to describe the kinetics of drying or to explain the physical stages involved in the drying process.

Drying kinetics generally refers to the fitting of measured drying properties such as drying rate, moisture content, temperature, drying time et cetera into empirical equations used for predicting the drying parameters and behaviours of materials at given conditions. According to Berbert, de Oliveira, and Martinazzo (2016), the drying characteristics of any product, including the mathematical models that best describe the process, are important in the selection and development of equipment as well as calculation of operating costs. Due to the difference in moisture content and transport phenomenon during dehydration in various food products, the drying kinetics of all food materials cannot be described by the same equation. Agarry, Ajani, and Aremu (2013) for instance, reported that the logarithmic model suitably describes the drying behaviour of blanched pineapples with goodness of fit of $\mathrm{R}^{2}>0.99$. Berbert et al. (2016) also reported that the single-exponential, three-parameter semi-theoretical drying model suitably predicted the drying curves of both fresh and pre-osmodehydrated pineapple slices.

A considerable amount of pineapples is produced in Mwinilunga district in the North-Western Province of Zambia. However the income derived from these pineapples is normally minimal due to inadequate preservation 
and storage facilities and also lack of marketing structures resulting in high post-harvest losses (Kennedy, 2016). Therefore as a means of adding value to pineapple production and reducing post-harvest losses, this study was aimed at investigating the drying kinetics of sliced pineapples using a solar conduction dryer, under weather conditions typical of Lusaka, Zambia. On the basis of its simplicity, lower cost and high efficiency the solar conduction dryer developed by a group of innovators called Science for Society (S4S) (http://scienceforsociety.co.in/solar-dryer/) was adapted for this study. The specific objectives were to:

I. investigate the effectiveness of the solar conduction dryer by comparing with open sun drying;

II. establish thin layer mathematical models that predict drying of pineapples at slice thickness of 3-5 $\mathrm{mm}, 5-7 \mathrm{~mm}$ and 7-10 $\mathrm{mm}$ under the solar conduction dryer;

III. determine the optimum fraction of drying tray area that should be loaded with pineapples enabling the remaining fraction to receive solar radiation; and

IV. determine the overall thermal efficiency of the solar conduction dryer.

\section{Materials and Methods}

\subsection{The Drying Unit}

The Solar Conduction Dryer (SCD) (figure1) uses solar energy which is transferred to the food through radiation, conduction and convection to dry the food. The structure of the dryer consisted of four drying chambers fabricated from wood (18 mm shatter ply) and four stainless steel drying trays where the pineapple slices to be dried were placed. A low height chimney to create air current was provided at the middle of the dryer along the longitudinal direction which also separated the drying chambers into two halves; each portion containing two drying trays. Atmospheric air entered from the front of the trays, carried away the moisture from the sample and exited through the chimney. The trays were overlaid with a black colour food grade coating. Each drying tray had a surface area of $0.1131 \mathrm{~m}^{2}$. Transparent and clear polyethylene plastic was used to enclose the trays in the four drying chambers. Loading and unloading were done by sliding the trays through the sides of the dryer. The original Solar Conduction Dryer was developed by a group of innovators known as Science for Society (S4S) and fabricated from hollow sections of stainless steel tubes (http://scienceforsociety.co.in/solar-dryer/) and was reported by Borah, Hazarika, and Khayer (2015) to have an efficiency of $55 \%$.

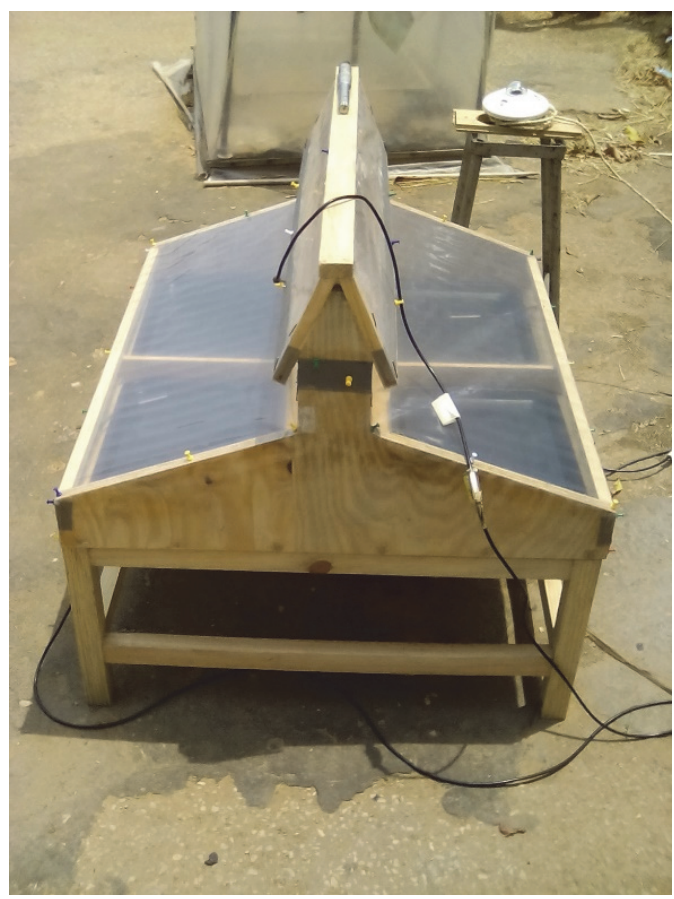

Figure 1. The Solar Conduction Dryer

\subsection{Instrumentation}

A multi-channel data logger (Campbell Scientific, Model CR1000) was used to measure solar radiation, relative 
humidity and temperature in the course of solar drying experiments. The multi-channel data logger consisted of a pyranometer (Kipp and Zonen, Model CM11, accuracy $\pm 0.5 \mathrm{~W} / \mathrm{m}^{2}$ ) placed on a horizontal surface near the dryer to measure solar radiation; a relative humidity probe (Model HMP60-L, accuracy $\pm 0.2 \%$ ) placed outside the dryer to measure ambient relative humidity; and three thermocouples (Campbell Scientific, Model T108, accuracy $\pm 0.2{ }^{\circ} \mathrm{C}$ ) measured the temperature. One of thermocouples was placed outside the dryer to measure ambient temperature; another was placed in the chimney to measure temperature in the dryer; and another to measure surface temperature of the drying trays. Data logger readings were accessed by connecting the data logger to a laptop computer. A digital airflow meter (Model TES 1340, accuracy $\pm 0.1 \mathrm{~m} / \mathrm{s}$ ) was used to measure ambient air velocity and air velocity inside the dryer. Weights of product samples at various times were measured using a digital balance (Metter, Model PE3000, accuracy $\pm 0.1 \mathrm{~g}$ ). An oven (Jeio Tech, Model ON-02G, accuracy, $\pm 0.5 \%$ ) was used in determining the initial moisture content of samples.

\subsection{Solar Drying Experiments}

The drying experiments were carried out at the Department of Agricultural Engineering field station at the University of Zambia with coordinates; Latitude $15.3^{\circ} \mathrm{S}$; Longitude $28.3^{\circ} \mathrm{E}$, with the dryer situated at a site with full exposure to sunshine. Moderately ripe pineapples (Smooth Cayenne) were bought from the local market, peeled and sliced into rings of desired thickness after which the central cores were removed from the slices. The slice thicknesses used for the experiments were $3 \mathrm{~mm}, 5 \mathrm{~mm}, 7 \mathrm{~mm}, 10 \mathrm{~mm}, 3-5 \mathrm{~mm}, 5-7 \mathrm{~mm}$, and 7-10 mm. Before solar drying, the initial moisture content of the samples were determined by oven-drying at $105{ }^{\circ} \mathrm{C}$ for 4 hours (AOAC, 2005). During solar drying, samples were weighed every 30 minutes until a fairly constant weight was achieved, and these weights were subsequently converted into moisture contents. Solar drying experiments usually started at 9:30 hours and ended at 16:30 hours each drying day. If at the end of a drying day an already started drying experiment had to be continued the next day, the drying plates with the pineapple slices on them were tightly wrapped with a cling wrap. Three main sets of experimental runs were carried out and each set was carried out in at least triplicates; the first set of experimental runs compared the performance of the Solar Conduction Dryer (SCD) with open sun drying; the second set involved developing thin layer drying models to predict the drying of sliced pineapples at different thicknesses under the Solar Conduction Dryer; and the third set involved investigating the fraction of drying tray area that should be covered with sliced pineapples with the remaining fraction of the tray available to absorb solar radiation. The first and second sets of experimental runs were carried out in November and December 2016 whilst the third set was carried out in February and March 2017.

\subsubsection{Comparing Solar Conduction Dryer with Open Sun Drying}

This set of experimental runs was carried out with 3-5 mm thickness of pineapple slices by loading all four drying trays at about 75 percent of tray area (Borah et al., 2015) with the remaining fraction of tray area exposed to solar radiation. Two of the drying trays were placed in the Solar Conduction Dryer (SCD) whilst the remaining two were placed on a raised platform by the side of the SCD. The sliced pineapples were then dried concurrently in thin layers under the same weather conditions using the SCD and open sun drying. The experiment was then repeated implying that this set of experimental runs was carried out in quadruplicate.

\subsubsection{Developing Thin Layer Drying Models to Predict Drying under the SCD}

With this set of experimental runs, the four drying trays were loaded at about 75 percent of their drying area (Borah et al., 2015) with each tray containing one of either $3 \mathrm{~mm}, 5 \mathrm{~mm}, 7 \mathrm{~mm}$ or $10 \mathrm{~mm}$ thickness of sliced pineapples in thin layers. These four thicknesses of sliced pineapples were dried concurrently under the same weather conditions in the four drying chambers of the SCD. This set of experimental runs was carried out in triplicates. The average dry basis moisture contents during the drying process were converted into moisture ratios using equation (1) (Agarry et al., 2013; Menges \& Ertekin, 2006; Toğrul \& Pehlivan, 2002):

$$
M R_{t}=\frac{m c_{t}(\% d . b .)}{m c_{0}(\% d . b .)}
$$

Where; $M R_{t}$ is the moisture ratio at any time $\mathrm{t}, m c_{t}$ is the percentage dry basis moisture content at any time $\mathrm{t}$, and $m c_{0}$ is the percentage dry basis initial moisture content of the samples.

The moisture ratios obtained for the four sample slice thicknesses were then plotted against drying time and the drying curves obtained were fitted with twelve different moisture ratio equations (table 1) using Microsoft Excel in-built Solver in non-linear regression mode. The primary criterion for selecting the best moisture ratio equation that defines the drying curves of sliced pineapples were the correlation coefficient $\left(\mathrm{R}^{2}\right)$, the reduced chi-square $\left(\chi^{2}\right)$ and the root mean square error (RMSE) (Agarry et al., 2013; Lahsasni, Kouhila, Mahrouz, \& Jaouhari, 2004; 
Menges \& Ertekin, 2006; Toğrul \& Pehlivan, 2002). These parameters are calculated as follows:

$$
\begin{gathered}
R^{2}=\frac{\sum_{i=1}^{N}\left(M R_{i, \text { exp }}-M R_{i, \text { exp.mean }}\right)^{2}-\Sigma_{i=1}^{N}\left(M R_{i, \text { pre }}-M R_{i, \text { exp }}\right)^{2}}{\sum_{i=1}^{N}\left(M R_{i, \text { exp }}-M R_{i, \text { exp.mean }}\right)^{2}} \\
\chi^{2}=\frac{\sum_{i=1}^{N}\left(M R_{i, \text { exp }}-M R_{i, \text { pre }}\right)^{2}}{N-n} \\
R M S E=\left[\frac{1}{N} \sum_{i=1}^{N}\left(M R_{i, \text { pre }}-M R_{i, \text { exp }}\right)^{2}\right]^{\frac{1}{2}}
\end{gathered}
$$

Where; $M R_{i, \text { exp }}$ is the ' $i$ 'th experimental moisture ratio, $M R_{i, p r e}$ is the ' $i$ 'th predicted moisture ratio, $M R_{i, \text { exp.mean }}$ is the mean value of experimental moisture ratios, $N$ is the number of observations, and $n$ is the number of constants in the moisture ratio equation.

The correlation coefficient $\left(R^{2}\right)$ gives the prediction ability of the model and its value varies between 0 and 1 , where the value closest to 1 represent the best fit. The reduced chi-square $\left(\chi^{2}\right)$ is used to determine the goodness of fit and the lower its value, the better the goodness of fit. The root mean square error (RMSE) gives the deviation between the predicted and experimental values and it is required to reach zero.

Table 1. Thin layer drying models

\begin{tabular}{ll}
\hline Diffusion approach & $\mathrm{MR}=\mathrm{a} \exp (-\mathrm{kt})+(1-\mathrm{a}) \exp (-\mathrm{kbt})$ \\
Henderson and Pabis & $\mathrm{MR}=\mathrm{a} \exp (-\mathrm{kt})$ \\
Logarithmic & $\mathrm{MR}=\mathrm{a} \exp (-\mathrm{kt})+\mathrm{c}$ \\
Middilli & $\mathrm{MR}=\mathrm{a} \exp \left(-\mathrm{kt} \mathrm{t}^{\mathrm{n}}\right)+\mathrm{bt}$ \\
Modified Henderson and Pabis & $\mathrm{MR}=\mathrm{a} \exp (-\mathrm{kt})+\mathrm{b} \exp (-\mathrm{gt})+\mathrm{c} \exp (-\mathrm{ht})$ \\
Modified Page & $\mathrm{MR}=\exp \left(-(\mathrm{kt})^{\mathrm{n}}\right)$ \\
Newton & $\mathrm{MR}=\exp (-\mathrm{kt})$ \\
Page & $\mathrm{MR}=\exp \left(-\mathrm{kt} \mathrm{t}^{\mathrm{n}}\right)$ \\
Two-term & $\mathrm{MR}=\mathrm{a} \exp \left(-\mathrm{k}_{0} \mathrm{t}\right)+\mathrm{b} \exp \left(-\mathrm{k}_{1} \mathrm{t}\right)$ \\
Two term exponential & $\mathrm{MR}=\mathrm{a} \exp (-\mathrm{kt})+(1-\mathrm{a}) \exp (-\mathrm{kat})$ \\
Wang and Singh & $\mathrm{MR}=1+\mathrm{at}+\mathrm{bt} \mathrm{t}^{2}$ \\
Wermal et al & $\mathrm{MR}=\mathrm{a} \exp (-\mathrm{kt})+(1-\mathrm{a}) \exp (-\mathrm{gt})$ \\
\hline
\end{tabular}

\subsubsection{Optimum Loading Area of Drying Tray}

Pineapple slices of $7 \mathrm{~mm}$ in thickness were used in this set of experimental runs. A fully loaded drying tray had on average of twelve pineapple slices. Hence three drying trays were loaded with the first tray containing twelve pineapple slices, the second containing nine pineapple slices and the third containing six pineapple slices, representing approximately 100, 75 and 50 percent of drying tray area, respectively. These three loading conditions were then ran simultaneously under the same weather conditions in the three drying chambers of the solar conduction dryer. This set of experimental runs was carried out in triplicates. The overall thermal efficiency of the drying process, which was calculated using equation 5 , was the criterion for the selection of the best loading condition.

$$
\eta=\frac{M h}{i A t}
$$

Where $M$ is the mass of water evaporated $(\mathrm{kg}), h$ is the latent heat of vaporisation at the dryer air temperature $(\mathrm{J} / \mathrm{kg}), i$ is the received solar radiation $\left(\mathrm{W} / \mathrm{m}^{2}\right), t$ is the drying time (s), and $A$ is the solar collection area $\left(\mathrm{m}^{2}\right)$.

\subsection{Experimental Uncertainties}

The results obtained from the drying experiments are associated with some uncertainties arising from inherent limitations of equipment used and the measurement technique. According to Özahi and Demir (2014), uncertainty analysis is conducted in order to confirm validity of measurements during all experiments. Uncertainty of any measurement can be evaluated by using the expression given below (Ebru Kavak Akpinar, 2006; E Kavak Akpinar, 2010; Holman \& Anderson, 1994): 


$$
U_{r}=\left[\left(\frac{\partial r}{\partial v_{1}} U_{1}\right)^{2}+\left(\frac{\partial r}{\partial v_{2}} U_{2}\right)^{2}+\cdots+\left(\frac{\partial r}{\partial v_{n}} U_{n}\right)^{2}\right]^{1 / 2}
$$

Where $U_{r}$ is uncertainty in the result, $\mathrm{r}$ is result as a function of independent variables $v_{1}, v_{2}, \ldots v_{n}$, and $U_{1}$, $U_{2}, \ldots U_{n}$ are uncertainties of independent variables. For instance the total uncertainty in the measurement of weight loss $\left(\mathrm{U}_{\mathrm{wl}}\right)$ can arise from uncertainty in reading $\left(\mathrm{U}_{\text {reading }}\right)$, uncertainty in digital balance $\left(\mathrm{U}_{\text {balance }}\right)$ and uncertainty caused by friction of tray $\left(\mathrm{U}_{\text {friction }}\right)$. That is:

$$
\begin{gathered}
U_{w l}=\left[\left(U_{\text {reading }}\right)^{2}+\left(U_{\text {balance }}\right)^{2}+\left(U_{\text {friction }}\right)^{2}\right]^{1 / 2} \\
U_{w l}=\left[(0.1)^{2}+(0.1)^{2}+(0.5)^{2}\right]^{1 / 2} \\
U_{w l}=0.5196
\end{gathered}
$$

During the measurements of the parameters, the uncertainties that occurred are presented in Table 2.

Table 2. Uncertainties of the measured parameters during drying experiments

\begin{tabular}{llll}
\hline Parameter & Unit & Uncertainties & \\
\hline & & Open sun drying & Solar dryer \\
Ambient air temperature & ${ }^{\circ} \mathrm{C}$ & \pm 0.2828 & \pm 0.2828 \\
Plate surface temperature & ${ }^{\circ} \mathrm{C}$ & & \pm 0.2828 \\
Temperature in chimney & ${ }^{\circ} \mathrm{C}$ & & \pm 0.2828 \\
Ambient relative humidity & $\%$ & \pm 0.2828 & \pm 0.2828 \\
Solar radiation & $\mathrm{W} / \mathrm{m}^{2}$ & \pm 0.5385 & \pm 0.5385 \\
Air velocity & $\mathrm{m} / \mathrm{s}$ & \pm 0.1414 & \pm 0.1414 \\
Weight loss & $\mathrm{g}$ & \pm 0.5196 & \pm 0.5196 \\
Initial moisture content & $\%$ & \pm 0.7211 & \pm 0.7211 \\
Time measurement of weight loss values & $\mathrm{min}$ & \pm 0.2 & \pm 0.2 \\
Reading values from steam table & $\%$ & \pm 0.2 & \pm 0.2 \\
Moisture ratio & $\%$ & & \pm 0.911 \\
Overall thermal efficiency & $\%$ & & \pm 0.8 \\
\hline
\end{tabular}

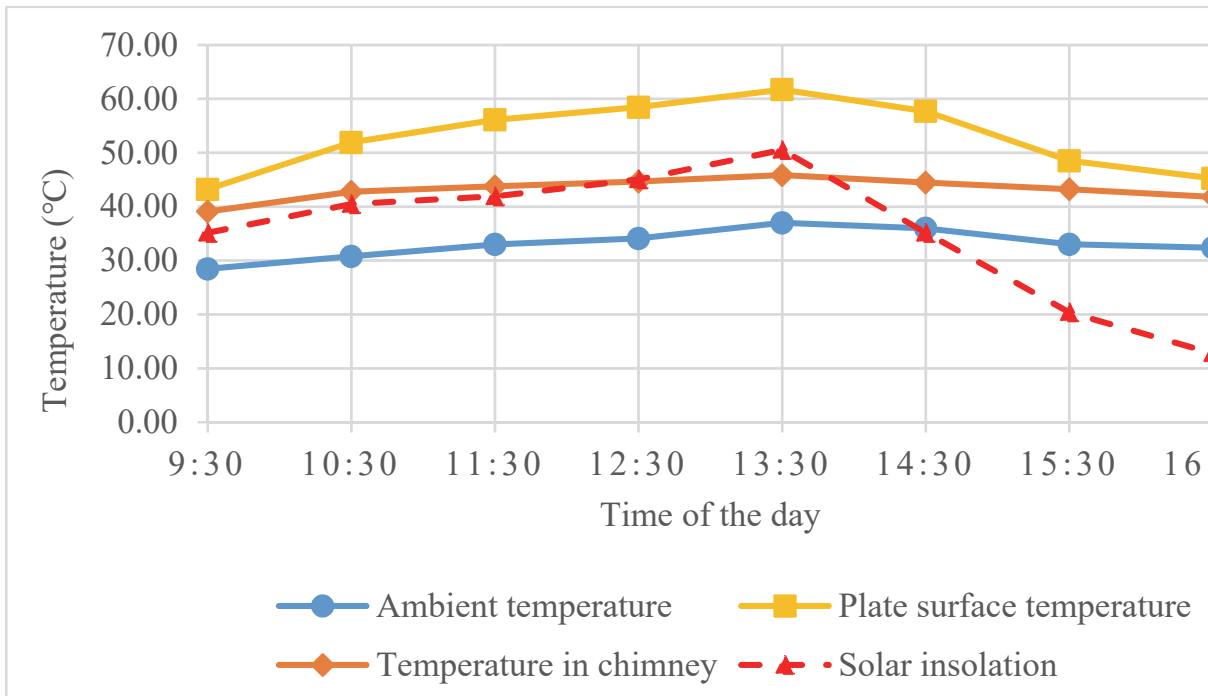

Figure 2. Mean daily solar insolation and mean daily temperatures recorded on a drying day for the period of November-December

\section{Results and Discussions}

\subsection{Initial Moisture Content}

The initial moisture content of the pineapple samples recorded during the three sets of experimental runs ranged 
from 85 to $91 \%$ (w.b.) which is comparable to the average initial moisture content of: $86 \%$ (w.b.) reported by Rodriguesa, da Silvab, and Chavesc (2010); and 87.32 \% (w.b.) reported by Bala et al. (2003).

\subsection{Climatic Conditions During the Period of Drying}

Figures 2 and 3 show the variation of drying temperature with solar radiation. The drying temperature in the SCD ranged from 39 to $45{ }^{\circ} \mathrm{C}$ for solar radiation range of 255 to $1011 \mathrm{~W} / \mathrm{m}^{2}$ during the period of November-December. Likewise the drying temperature in the SCD for the period of February-March ranged from 24 to $42{ }^{\circ} \mathrm{C}$ whereas solar radiation ranged from 263 to $843 \mathrm{~W} / \mathrm{m}^{2}$.

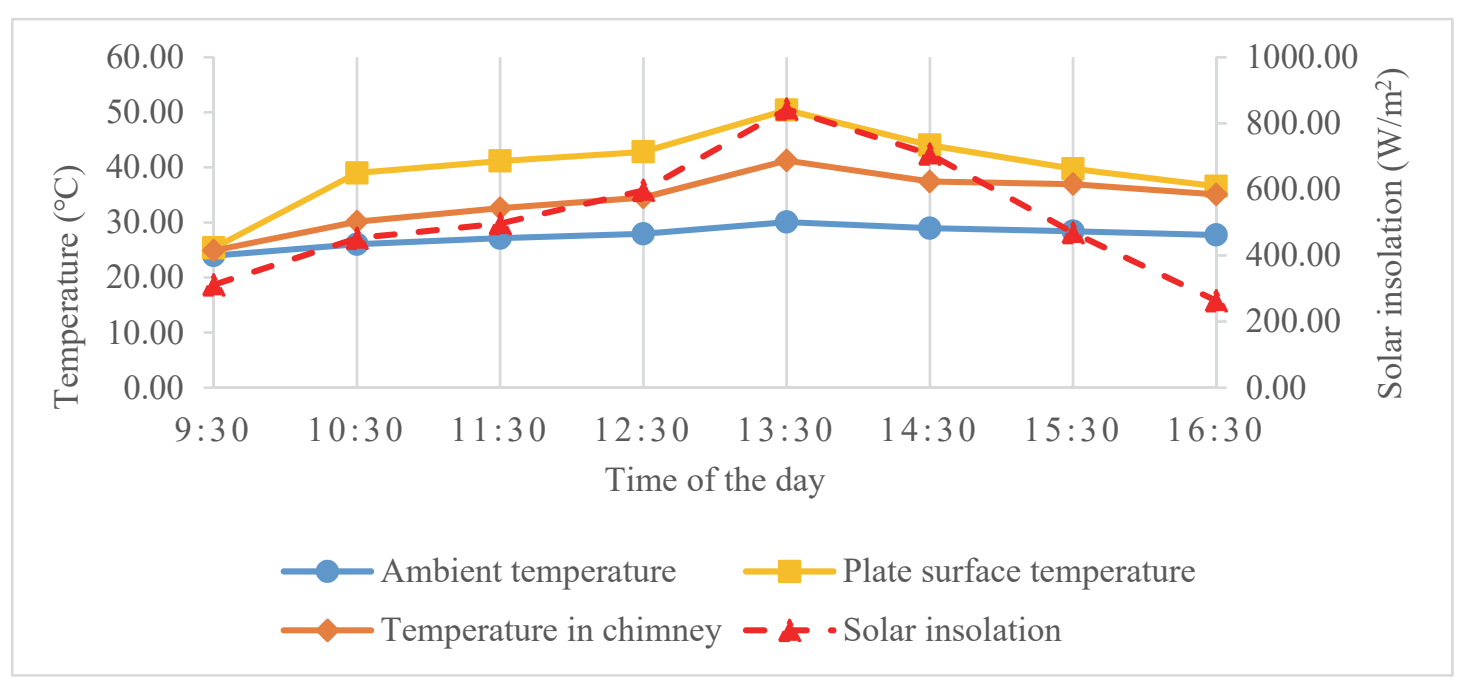

Figure 3. Mean daily solar insolation and mean daily temperatures recorded on a drying day for the period of February-March

\subsection{Comparing Solar Conduction Dryer with Sun Drying}

Figure 4 shows the variation of moisture content with drying time for slice samples dried simultaneously under the Solar Conduction Dryer and Open-sun. From an average moisture content of $85.42 \%$ (w.b.), samples were reduced to a moisture content of $12.23 \%$ (w.b.) by the solar conduction dryer and to $51.51 \%$ (w.b.) by open-sun drying in 8 hours effective drying time. This suggests that samples in the Solar Conduction Dryer had a higher drying rate than those of open-sun drying due to the higher drying air temperature in the Solar Conduction Dryer as compared to ambient air temperature. The drying rate for the sliced samples in the solar conduction dryer was initially faster up to about 5.5 hours of elapsed drying time as can be seen in figure 4 . This was due to high amount of free moisture availability, which was easily removed in the initial stage of drying (Gaware, Sutar, \& Thorat, 2010). Subsequently, the drying rate became slow as the drying progressed beyond 5.5 hours of elapsed drying time. Similar results were observed for the drying of pineapples as reported by Bala, Mondol, Biswas, Chowdury, and Janjai (2003); drying of sliced turmeric rhizomes as reported by Borah et al. (2015); drying of sliced mangoes as reported by Cherotich and Simate (2016), drying of fresh Kapenta as reported by Aduke and Simate (2016); drying of golden apples as reported by Menges and Ertekin (2006); drying of apricots as reported by Toğrul and Pehlivan (2002); and drying of prickly pear fruit as reported by Lahsasni et al. (2004).

The results of SCD and open-sun drying comparison were comparable to one reported by Bala et al. (2003) where for an average solar radiation of $580 \mathrm{~W} / \mathrm{m}^{2}$ and dryer temperature range of 34.1 to $64{ }^{\circ} \mathrm{C}$, sulphur treated pineapple slices of $10 \mathrm{~mm}$ thickness were simultaneously dried by a solar tunnel drier and traditional open sun drying from an initial moisture content of $87.32 \%$ (w.b.), to a final moisture content of 14.13 and $21.52 \%$ (w.b) respectively in 3 days. 


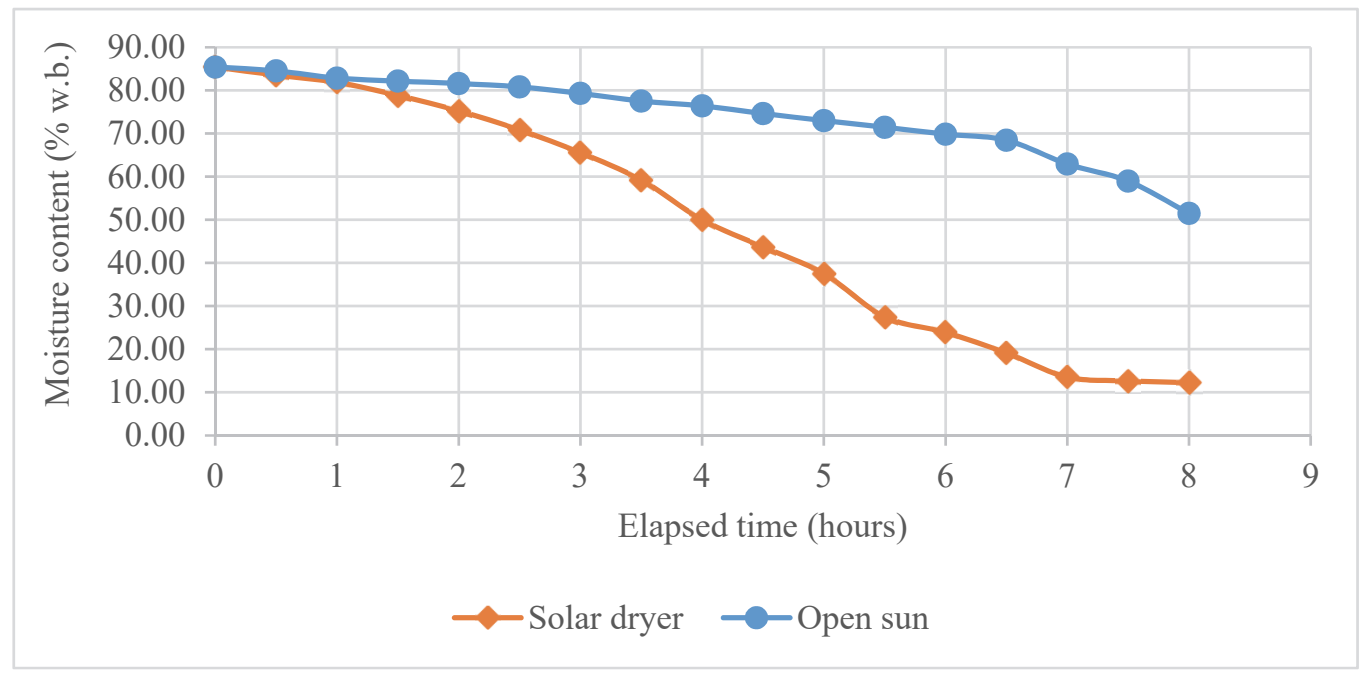

Figure 4. Variation of moisture content with drying time under the Solar Conduction Dryer and Open-sun

\subsection{Thin Layer Drying Modelling}

Figure 5 shows how the moisture content for the various sample thicknesses varied with drying time. From an average moisture content of $85.57 \%$ (w.b.); the $3 \mathrm{~mm}$ slices were reduced to $13.42 \%$ (w.b.) in 7 hours effective drying time; the $5 \mathrm{~mm}$ sample slices were reduced to $13.07 \%$ (w.b.) in 9.5 hours of effective drying; the $7 \mathrm{~mm}$ sample slices were reduced to $13.79 \%$ (w.b.) after 11 hours of effective drying; and the $10 \mathrm{~mm}$ sample slices were reduced to $14.69 \%$ (w.b.) after 14 hours of effective drying. It was therefore evident that the rate of drying was faster for samples of smaller slice thickness than those of larger slice thickness. This was because as pineapple slices get thicker, the distance from the centre to the surface of the slices increases. When the distance increases, the time it takes for water to move from the centre to the surface of the slices also increases and subsequently the energy required to move water from the centre to the surface of the slices also increased. Similar results were reported for the drying of banana slices and apple slices at different slice thicknesses by Mercer (2012).

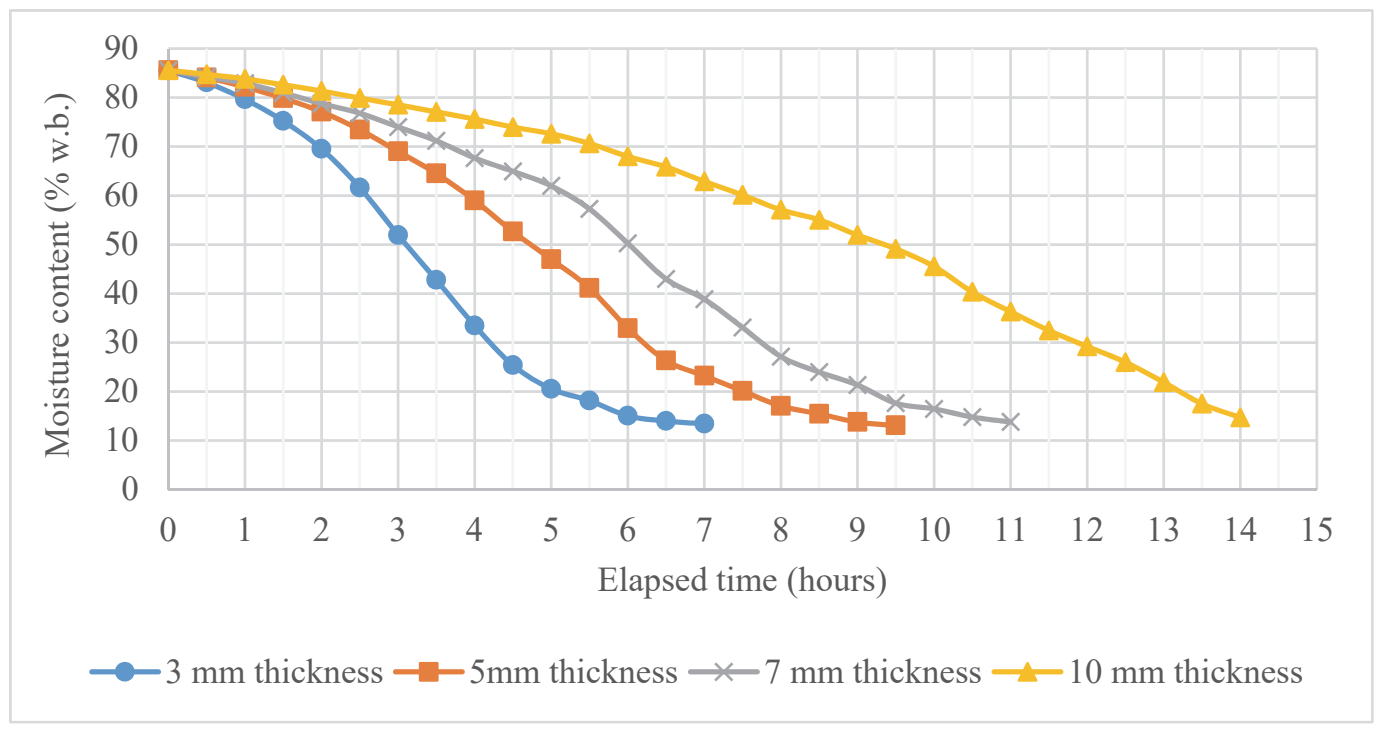

Figure 5. Variation of moisture content with drying time at different slice thicknesses

The moisture content curves were converted to moisture ratio curves as shown in figure 6 . 


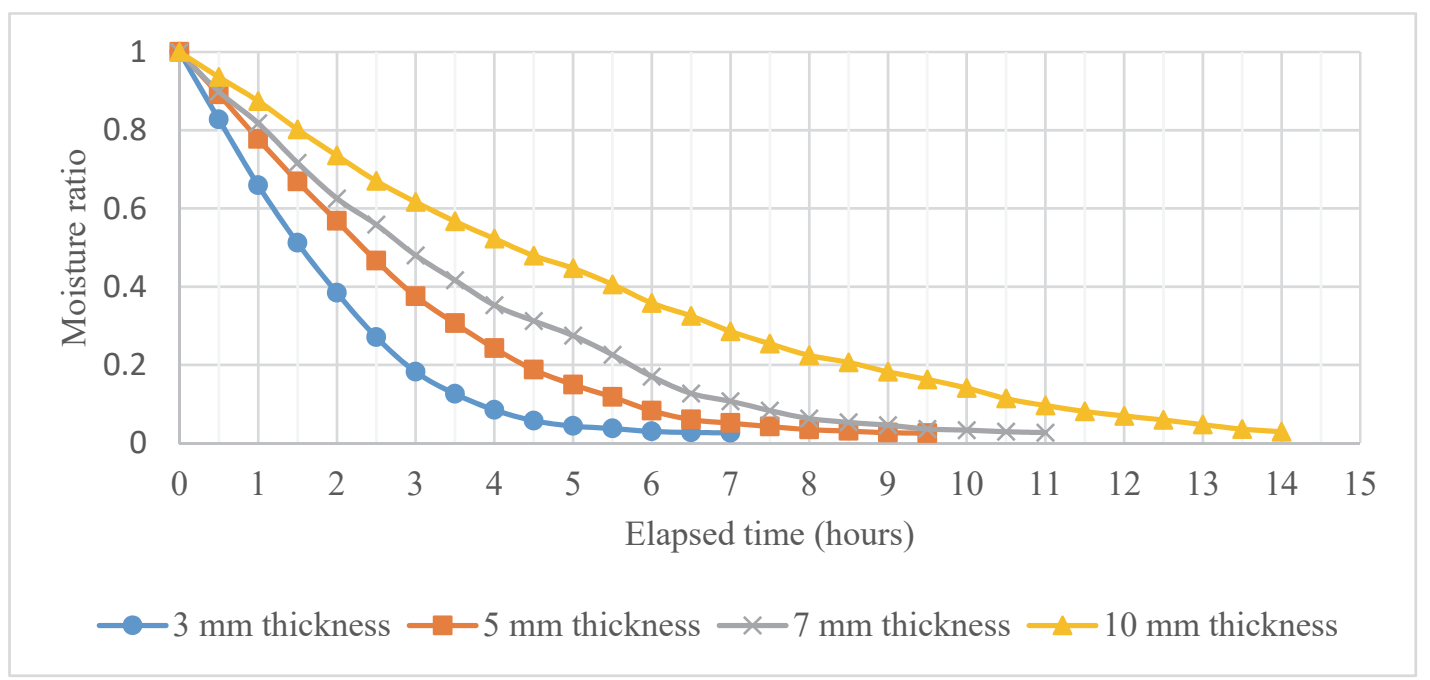

Figure 6. Variation of moisture ratio with drying time for the four sample slice thicknesses

After fitting the moisture ratio curves with the twelve thin layer drying equations (table 1) using Microsoft Excel in-built solver, it was observed that all twelve models gave a considerably good fit for all the four sample slice thicknesses. For all the twelve models under all four sample slice thicknesses; correlation coefficient $\left(\mathrm{R}^{2}\right)$ ranged from 0.9843 to 0.9996 , reduced chi-square $\left(\chi^{2}\right)$ ranged from 0.0018 to 0.00004 ; and root mean square error (RMSE) ranged from 0.0387 to 0.0057 . However, the order of best fit of the twelve thin layer drying models was not the same across all four sample slice thicknesses as can be seen in tables 3, 4,5 and 6. The Midilli model among all the other models proved the most consistent across all four sample slice thicknesses with; correlation coefficient $\left(\mathrm{R}^{2}\right)$ ranging from 0.9986 to 0.9996 ; reduced chi-square $\left(\chi^{2}\right)$ ranging from 0.0002 to 0.00004 ; and root mean square error (RMSE) ranging from 0.0115 to 0.0057 .

Agarry et al. (2013) reported that among the Page, Henderson and Pabis, Logarithmic and Two-term thin layer drying models, the Logarithmic model best describes the drying behaviour of blanched pineapple slices with goodness of fit $\mathrm{R}^{2}$ greater than 0.99 . Berbert et al. (2016) also reported 'the single-exponential, three-parameter semi-theoretical' drying model gives a satisfactory prediction of the drying curves of pineapple slices both in fresh and pre-osmodehydrated samples.

Table 3. Thin layer drying modelling results for $3 \mathrm{~mm}$ thickness sample slices in order of best fit

\begin{tabular}{lccc}
\hline \multirow{2}{*}{ DRYING MODEL } & \multicolumn{3}{c}{ CRITERIA } \\
\cline { 2 - 4 } Middilli & $\mathrm{R}^{2}$ & $\chi^{2}$ & RMSE \\
\cline { 2 - 4 } Werma et al & 0.9994 & 0.00008 & 0.0079 \\
Diffusion approach & 0.9991 & 0.0001 & 0.0093 \\
Two term exponential & 0.9991 & 0.0001 & 0.0093 \\
Page & 0.9990 & 0.0001 & 0.0099 \\
Modified Page & 0.9990 & 0.0001 & 0.0099 \\
Wang and Singh & 0.9990 & 0.0001 & 0.0099 \\
Logarithmic & 0.9943 & 0.0006 & 0.0236 \\
Henderson and Pabis & 0.9935 & 0.0008 & 0.0251 \\
Two-term & 0.9906 & 0.0010 & 0.0301 \\
Modified Henderson and Pabis & 0.9906 & 0.0012 & 0.0301 \\
Newton & 0.9906 & 0.0015 & 0.0301 \\
\hline
\end{tabular}

Table 4. Thin layer drying modelling results for $5 \mathrm{~mm}$ thickness sample slices in order of best fit

\begin{tabular}{llll}
\hline DRYING MODEL & \multicolumn{3}{l}{ CRITERIA } \\
\cline { 2 - 3 } & $\mathrm{R}^{2}$ & $\chi^{2}$ & RMSE \\
\hline
\end{tabular}




\begin{tabular}{llll}
\hline Middilli & 0.9996 & 0.000051 & 0.0064 \\
Page drying & 0.9995 & 0.000053 & 0.0069 \\
Modified Page & 0.9995 & 0.000053 & 0.0069 \\
Two term exponential & 0.9993 & 0.00007 & 0.00797 \\
Wang and Singh & 0.9978 & 0.0002 & 0.0144 \\
Two-term & 0.9955 & 0.0005 & 0.0206 \\
Logarithmic & 0.9945 & 0.0006 & 0.0229 \\
Henderson and Pabis & 0.9893 & 0.0011 & 0.0319 \\
Modified Henderson and Pabis & 0.9893 & 0.0015 & 0.0319 \\
Newton & 0.9843 & 0.0016 & 0.0387 \\
Diffusion approach & 0.9843 & 0.0018 & 0.0387 \\
Werma et al & 0.9843 & 0.0018 & 0.0387 \\
\hline
\end{tabular}

Table 5. Thin layer drying modelling results for $7 \mathrm{~mm}$ thickness sample slices in order of best fit

\begin{tabular}{llll}
\hline DRYING MODEL & \multicolumn{3}{l}{ CRITERIA } \\
\cline { 2 - 4 } Wang and Singh & $\mathrm{R}^{2}$ & $\chi^{2}$ & $\mathrm{RMSE}$ \\
\cline { 2 - 4 } Middilli & 0.9990 & 0.0001 & 0.0095 \\
Page & 0.9986 & 0.0002 & 0.0115 \\
Modified Page & 0.9980 & 0.0002 & 0.0134 \\
Two-term exponential & 0.9980 & 0.0002 & 0.0134 \\
Logarithmic & 0.9977 & 0.0002 & 0.0145 \\
Henderson and Pabis & 0.9966 & 0.0004 & 0.0177 \\
Two-term & 0.9892 & 0.0011 & 0.0315 \\
Modified Henderson and Pabis & 0.9892 & 0.0012 & 0.0315 \\
Newton & 0.9892 & 0.0013 & 0.0315 \\
Diffusion approach & 0.9851 & 0.0014 & 0.0369 \\
Werma et al & 0.9851 & 0.0016 & 0.0369 \\
\hline
\end{tabular}

Table 6. Thin layer drying modelling results for $10 \mathrm{~mm}$ thickness sample slices in order of best fit

\begin{tabular}{llll}
\hline DRYING MODEL & \multicolumn{3}{l}{ CRITERIA } \\
\cline { 2 - 4 } & $\mathrm{R}^{2}$ & $\chi^{2}$ & $\mathrm{RMSE}$ \\
\cline { 2 - 4 } Middilli & 0.9996 & 0.00004 & 0.0057 \\
Logarithmic & 0.9995 & 0.00005 & 0.0068 \\
Wang and Singh & 0.9988 & 0.0001 & 0.0101 \\
Page drying & 0.9977 & 0.0002 & 0.0140 \\
Modified Page & 0.9977 & 0.0002 & 0.0140 \\
Two-term exponential & 0.9975 & 0.0002 & 0.0145 \\
Henderson and Pabis & 0.9906 & 0.00086 & 0.0283 \\
Two-term & 0.9906 & 0.00093 & 0.0283 \\
Modified Henderson and Pabis & 0.9906 & 0.0010 & 0.0283 \\
Newton & 0.9867 & 0.0012 & 0.0336 \\
Diffusion approach & 0.9867 & 0.0013 & 0.0336 \\
Werma et al & 0.9867 & 0.0013 & 0.0336 \\
\hline
\end{tabular}

After simulating the experimental moisture ratios with the twelve thin layer drying equations (table 1), the equations generated for the Midilli drying model is presented in table 7 . The average values of the model constants for the 3,5,7 and $10 \mathrm{~mm}$ thickness sample slices were used to estimate the model constants for drying sliced pineapples at thicknesses 3-5, 5-7 and 7-10 mm. " $M R$ " in the equations in table 6 represent moisture ratio whilst " $t$ " represent drying time in hours. 
Table 7. Thin layer drying mathematical models generated from the simulation process

1. Drying model for $3 \mathbf{~ m m}$ slices
$M R=0.990879078 \exp \left(-0.402482539 \times t^{1.308425080}\right)+0.002163041 t$

2. Drying model for $5 \mathbf{~ m m}$ slices

$M R=0.995179673 \exp \left(-0.237220830 \times t^{1.295665045}\right)+0.000549481 t$

3. Drying model for $7 \mathbf{~ m m}$ slices
$M R=0.987138837 \exp \left(-0.185832538 \times t^{1.224004005}\right)-0.001690207 t$

4. Drying model for $10 \mathrm{~mm}$ slices

$M R=0.999801427 \exp \left(-0.135613724 \times t^{1.088001638}\right)-0.004994724 t$

5. Drying model for 3-5 $\mathbf{~ m m}$ slices

$M R=0.993029375 \exp \left(-0.319851685 \times t^{1.302045063}\right)+0.001356261 t$

6. Drying model for 5-7 $\mathbf{~ m m}$ slices

$M R=0.991159255 \exp \left(-0.211526684 \times t^{1.259834525}\right)-0.000570363 t$

\section{Drying model for $\mathbf{7 - 1 0} \mathbf{~ m m}$ slices}

$M R=0.993470132 \exp \left(-0.160723131 \times t^{1.156002822}\right)-0.003342465 t$

For the objectives of the study, equations V, VI and VII from table 6 were the ones of interest hence these equations were validated against experimental results by drying pineapple slice samples of thicknesses 3-5, 5-7 and 7-10 mm. Figures 7, 8 and 9 show the results of the validation procedure.

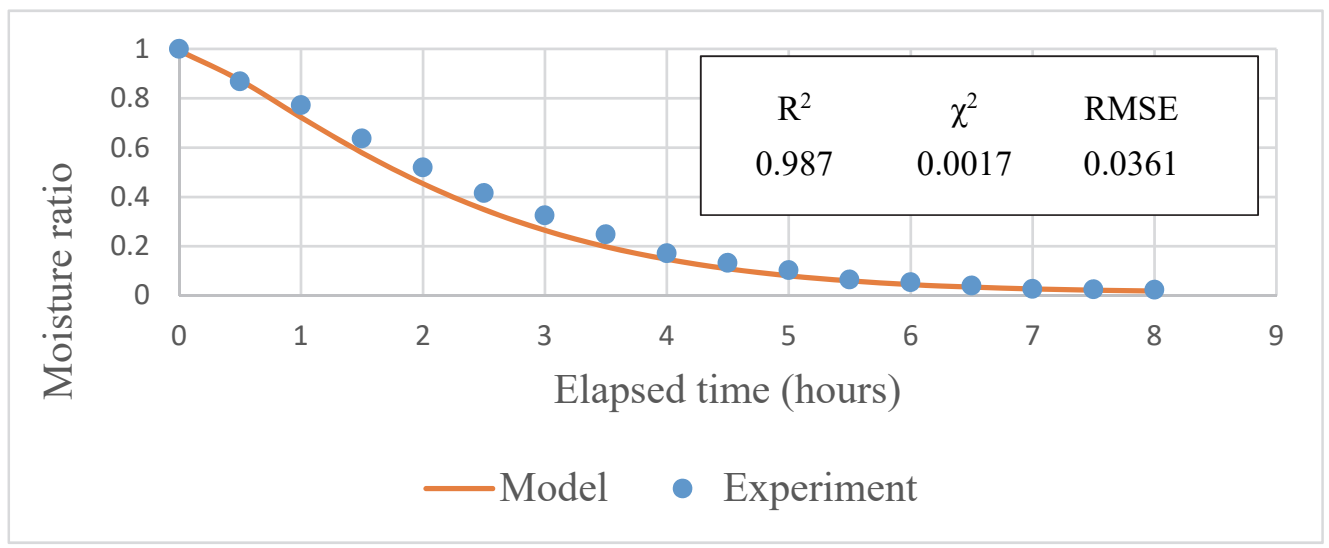

Figure 7. Validation results for 3-5 $\mathrm{mm}$ slice thickness model

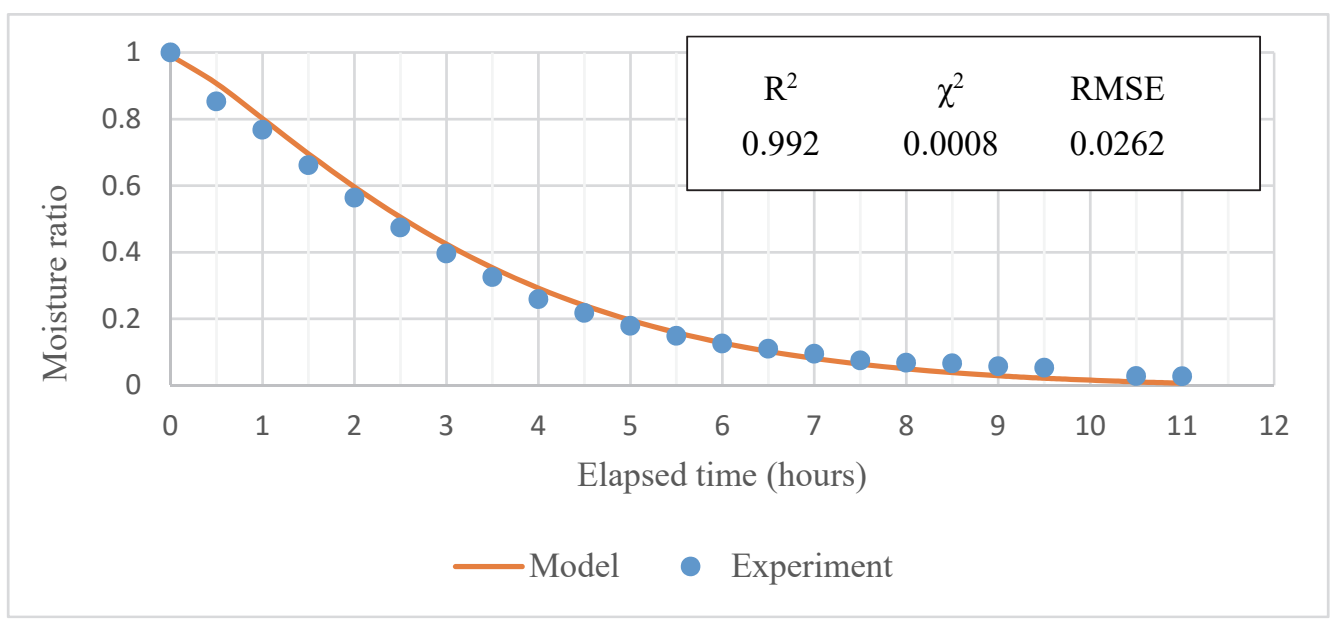

Figure 8. Validation results for 5-7 $\mathrm{mm}$ slice thickness model 


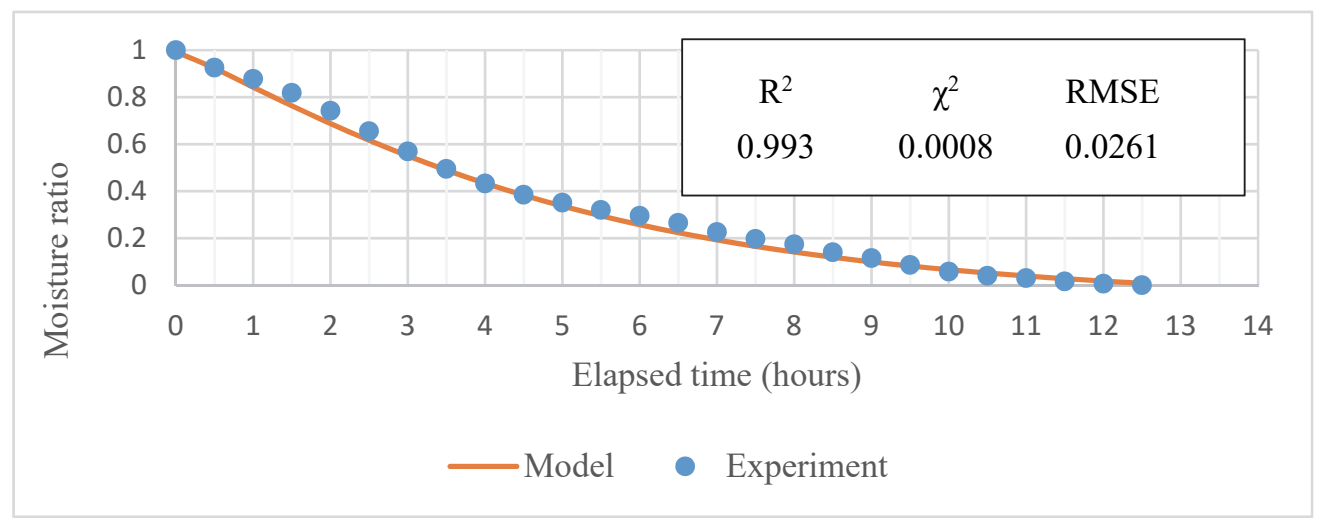

Figure 9. Validation results for 7-10 mm slice thickness model

\subsection{Optimum Loading Area of Drying Tray}

Figure 10 shows the variation of moisture content with drying time by loading pineapple slices of $7 \mathrm{~mm}$ thickness at approximately 50, 75 and 100 percent of drying tray area. After 11.5 hours of effective drying, samples loaded at 50 percent drying tray area had been reduced from an average moisture content of 85.21 to $7.24 \%$ (w.b.) whereas samples loaded at 75 percent drying tray area had been reduced to $10.61 \%$ (w.b.), and samples loaded at 100 percent drying tray area reduced to $11.47 \%$ (w.b.) from the same initial moisture content of $85.21 \%$ (w.b.). Sliced pineapple samples were observed to be shrinking in the course of drying such that samples that were loaded at 100 percent drying tray area ended up covering about 75-80 percent of drying tray area and those loaded at 75 percent of drying tray area ending up covering just about 50-60 percent drying tray area. There was no substantial difference in the rate at which samples loaded at both 75 and 100 percent of drying tray area were dried as can be seen in fig 4.15. However the rate at which sample slices loaded at 50 percent drying tray area was dried was considerably faster than those loaded at 75 and 100 percent of drying tray area confirming the significance of the conduction of heat through the trays in the drying process.

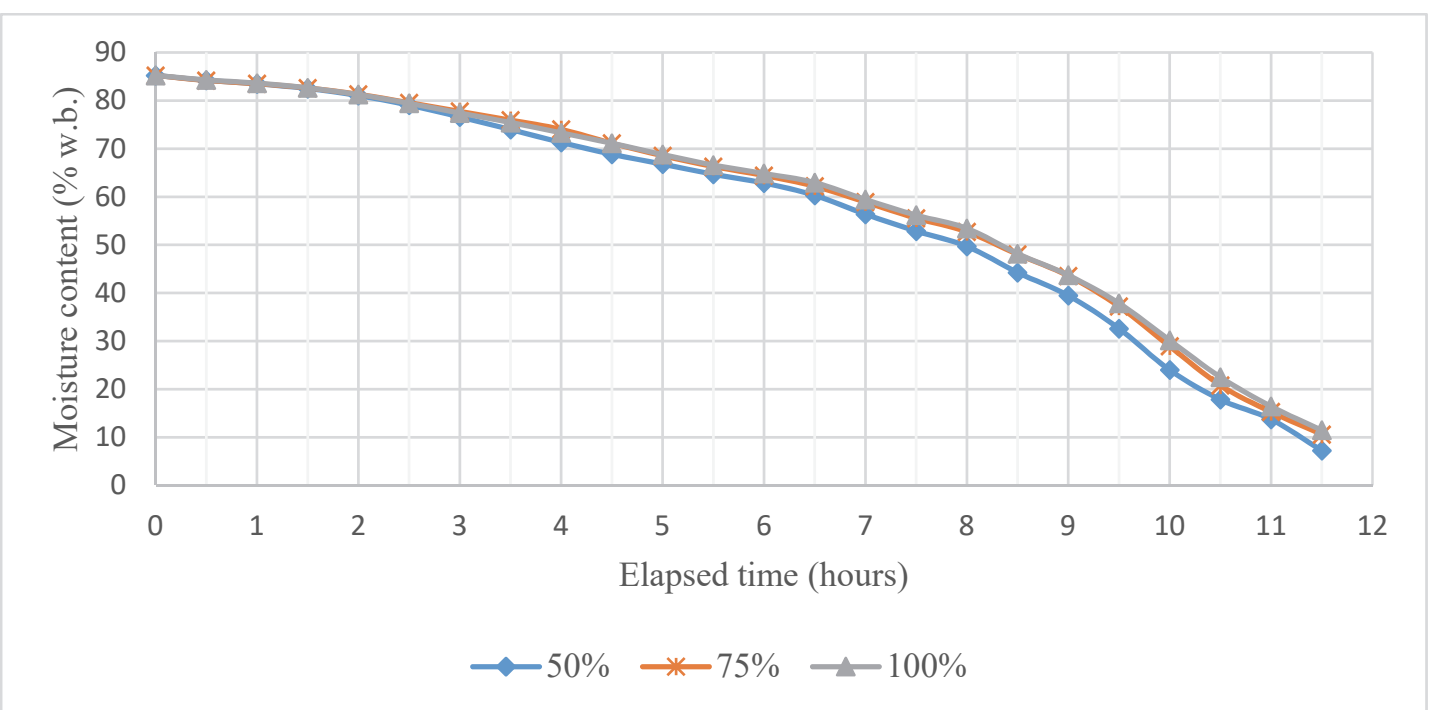

Figure 8. Variation of moisture content with drying time for loading at different fractions of drying tray area

Loading at 50, 75, and 100 percent of drying tray area respectively removed an average of $0.1961,0.2739$, and $0.3779 \mathrm{~kg}$ of water after 11.5 hours of effective drying. The average solar insolation received and the average temperature in the dryer at the period of this set of experimental runs were found to be $517.44 \mathrm{~W} / \mathrm{m}^{2}$ and $34.12{ }^{\circ} \mathrm{C}$ respectively. The latent heat of vaporisation at this drying air temperature was found from a steam table to be $2563.02 \mathrm{~kJ} / \mathrm{kg}$. The air flow vent at the centre of the dryer caused a shadow effect on the drying trays with change in position of sun during a drying day. In view of this, an assumptive calculation was done considering 
90 percent (Borah et al., 2015) of the actual drying tray area $(0.29 \mathrm{~m} \times 0.39 \mathrm{~m})$ resulting in $0.10179 \mathrm{~m}^{2}$ effective area available for drying. The overall thermal efficiencies for the three loading conditions were then calculated using equation (5). Loading sliced samples at 50, 75, and 100 percent drying tray area therefore gave overall thermal efficiencies of $23.05,32.19$ and 44.42 percent respectively. This implies that loading pineapple slices at 100 percent drying tray area utilises more of the received solar radiation than loading at only a fraction of the drying tray area. However, since loading at 50,75 and 100 percent drying tray area implied loading at different weights of sliced pineapples, it was imperative to compare the efficiencies at these three loading conditions with the weight of sliced pineapples loaded in each case. The average weight of slice samples recorded for loading at 50,75 and 100 percent drying tray area were $0.2333,0.3282$, and $0.4537 \mathrm{~kg}$ respectively. For an average initial moisture content of $85.21 \%$ w.b., the initial weight of water in sliced samples (before drying) for the three loading conditions of 50,75 and 100 percent drying tray area were $0.198795,0.279659$, and 0.386598 respectively. Considering that loading at 50,75 , and 100 percent of drying tray area removed an average of $0.1961,0.2739$, and $0.3779 \mathrm{~kg}$ of water respectively after 11.5 hours of effective drying, it implied that the percentage of total moisture that had been removed after 11.5 hours of effective drying were 98.64, 97.94 and 97.75 percent, for loading at 50,75 and 100 percent drying tray area respectively. This implies that in general, the moisture removal rate in drying samples are higher when the drying tray is only partially loaded with the remaining fraction exposed to receive solar radiation. However, in the case of sliced pineapple samples, shrinking of slices in the course of drying makes available more space on the drying tray to receive solar radiation. Drying samples in a solar conduction dryer utilise solar energy by absorption of shortwave radiation by the crop itself and also by the drying trays. Hence with sliced pineapple samples, loading at 100 percent drying tray area enable more slices to receive shortwave radiation at the same time as the space created on the drying tray by the shrinking of the slices in the course of drying, thereby capturing more shortwave radiation by the drying trays. With Sodha, Bansal, Kumar, Bansal, and Malik (1987) reporting that the efficiency of most solar dryers ranges between 30 and $50 \%$, it can be concluded that the SCD is comparatively very efficient

\section{Conclusion}

Throughout the drying experiments, temperature in the SCD was always significantly higher than that in the ambient. The drying conditions achieved in the SCD are very ideal for drying sliced pineapples as they compare favourably with what other researchers have reported. The SCD was more effective in moisture removal than open sun drying as it took less time. The Midilli-Kucuk model is the best model for predicting the drying behaviour of sliced pineapples under the SCD since it proved to be the most consistent model. Loading SCD at 100 percent drying tray area produces the highest overall thermal efficiency compared to loading at 50 and 75 percent drying tray area.

\section{Acknowledgement}

The authors acknowledge the funding from the European Commission through the METEGA-Intra-ACP Academic Mobility Scheme to enable the first author to undertake the MEng. study.

\section{References}

Aduke, R. N., \& Simate, I. N. (2016). Greenhouse Solar Drying and Thin Layer Drying Of Fresh Kapenta (Stolothrissa tanganicae). International Journal of Scientific \& Engineering Research, 7(5).

Agarry, S., Ajani, A., \& Aremu, M. (2013). Thin layer drying kinetics of pineapple: Effect of blanching temperature-time combination. Nigerian Journal of Basic and Applied Sciences, 21(1), 1-10.

Akpinar, E. K. (2006). Determination of suitable thin layer drying curve model for some vegetables and fruits. Journal of Food Engineering, 73(1), 75-84.

Akpinar, E. K. (2010). Drying of mint leaves in a solar dryer and under open sun: modelling, performance analyses. Energy Conversion and Management, 51(12), 2407-2418.

AOAC. (2005). Latimer JW, Horwitz W, editors. Official methods of analysis: Washington DC, AOAC International press.

Bala, B., Mondol, M., Biswas, B., Chowdury, B. D., \& Janjai, S. (2003). Solar drying of pineapple using solar tunnel drier. Renewable Energy, 28(2), 183-190.

Barnell, H. R. (1974). Biology and the food industry: Edward Arnold (Publishers) Ltd.

Berbert, P. A., de Oliveira, M. T. R., \& Martinazzo, A. P. (2016). Drying of pineapple slices in natura and pre-osmodehydrated in inverted sugar $=$ Secagem de fatias de abacaxi in natura e pré-desidratadas osmoticamente em açúcar invertido. Bioscience Journal, 32(3). 
Borah, A., Hazarika, K., \& Khayer, S. M. (2015). Drying kinetics of whole and sliced turmeric rhizomes (Curcuma longa L.) in a solar conduction dryer. Information Processing in Agriculture, 2(2), 85-92. doi: http://dx.doi.org/10.1016/j.inpa.2015.06.002

Cherotich, S., \& Simate, I. N. (2016). Experimental Investigation and Mathematical Modelling of a Natural Convection Solar Tunnel Dryer. International Journal of Scientific \& Engineering Research, 7(5).

Esper, A. (1996). Solar tunnel dryer for fruits. Plant Research and Development, 44, 61-80.

Gaware, T., Sutar, N., \& Thorat, B. (2010). Drying of tomato using different methods: comparison of dehydration and rehydration kinetics. Drying technology, 28(5), 651-658.

Holman, J., \& Anderson, A. M. (1994). Experimental Methods for Engineers. Experimental Thermal and Fluid Science, 9(2), 250-250.

Ihekoronye, A. I., \& Ngoddy, P. O. (1985). Integrated food science and technology for the tropics: Macmillan.

Kennedy. (2016, 9th March 2016). Zambia: Farmers Shun Pineapple Growing. Times of Zambia. Retrieved from http://allafrica.com/stories/201603100109.html

Lahsasni, S., Kouhila, M., Mahrouz, M., \& Jaouhari, J. (2004). Drying kinetics of prickly pear fruit (Opuntia ficus indica). Journal of Food Engineering, 61(2), 173-179.

Menges, H. O., \& Ertekin, C. (2006). Mathematical modeling of thin layer drying of Golden apples. Journal of Food Engineering, 77(1), 119-125.

Mercer, D. (2012). A Basic Guide to Drying Fruits and Vegetables: University of Guelph, Ontario, Canada.

Özahi, E., \& Demir, H. (2014). Presentation of a test rig with its experimental procedure and uncertainty analysis of measurements for batch type fluidized bed drying of corn and unshelled pistachio nut. Measurement, 53, 117-127.

Rodriguesa, E., da Silvab, J. N., \& Chavesc, M. A. (2010). Modelling the Drying Kinetics of Pineapple Slices in a Tray Dryer.

Sodha, M., Bansal, N., Kumar, A., Bansal, P., \& Malik, M. (1987). Solar Crop Drying, Vol. II: CPR press, Boca Raton, Florida, USA.

Toğrul, İ. T., \& Pehlivan, D. (2002). Mathematical modelling of solar drying of apricots in thin layers. Journal of Food Engineering, 55(3), 209-216.

\section{Copyrights}

Copyright for this article is retained by the author(s), with first publication rights granted to the journal.

This is an open-access article distributed under the terms and conditions of the Creative Commons Attribution license (http://creativecommons.org/licenses/by/4.0/). 